\title{
Ultrasound Guidance for Lumbar Puncture: A Consideration, Not an Obligation
}

\author{
Tiffany C Fong, MD ${ }^{1 *}$, Andrew D Auerbach, MD, MPH ${ }^{2}$
}

'Department of Emergency Medicine, Johns Hopkins University School of Medicine, Baltimore, Maryland; ${ }^{2}$ Division of Hospital Medicine, University of California, San Francisco, San Francisco, California.

ecognizing the increasingly important role of point-ofcare ultrasound (POCUS) in advancing clinical care, the Society of Hospital Medicine (SHM) has published a valuable series of position statements to guide hospitalists and administrators on the safe and effective use of POCUS. In this issue of the Journal of Hospital Medicine, Soni et al. present a series of consensus-based recommendations on ultrasound guidance for lumbar puncture (LP). ${ }^{2}$ Among these are the recommendations that ultrasound "should be used" to map the lumbar spine and to select an appropriate puncture site to reduce insertion attempts, reduce needle redirections, and increase overall procedural success.

At first glance, the recommendations appear definitive. However, not immediately obvious is the authors' clarification that "This position statement does not mandate that hospitalists use ultrasound guidance for LP, nor does it establish ultrasound guidance as the standard of care for LP." Even with the authors' caveat, this nuance may not be readily apparent to the readers who review only the executive summary of the guidelines or who omit the context provided in the background of the position statement.

The directive language of this position statement may be a result of an unmerited amplification. The SHM POCUS Task Force employed the Research and Development Appropriateness Method to quantify the degree of consensus and the strength of the recommendation assigned, ${ }_{1}^{3}$ reaching "very good" consensus for each of the recommendations espoused in its position statement. Procedurally, this implies that $\geq 80 \%$ of the 27 voting members rated each published recommendation statement as "appropriate". Using wording assigned a priori by the committee to each level of consensus, appropriateness became magnified to the declaration "should be used". In this manner, the strength of the recommendations in this position statement is not necessarily based on the experts' convictions related to ultrasound-guided LP, nor the strength of the supporting evidence.

In the case of ultrasound-guided LP, we might choose different descriptors than "appropriate" or "should be used". The evidence base for ultrasound guidance for $L P$, though growing, may be insufficient as a foundation to a position statement and is certainly insufficient to create a new standard of care for

Corresponding Author: Tiffany C Fong, MD; E-mail: tfong3@jhmi.edu; Telephone: 410- 955-8708.

Received: May 30, 2019; Accepted: June 2, 2019

๑ 2019 Society of Hospital Medicine DOI 10.12788/jhm.3259 hospitalists. Although the SHM POCUS Task Force completed a thoughtful literature review, no systematic approach (eg, GRADE methodology ${ }^{4}$ ) was used to rate the quality of evidence. Furthermore, the literature reviewed was drawn predominantly from anesthesia and emergency medicine sources_-not readily generalizable to the hospitalist. Notably, these studies examined all neuraxial procedures (most commonly epidural and spinal anesthesia), which employ different techniques and tools than LP and are performed by clinicians with vastly different procedural training backgrounds than most hospitalists. Altogether, this creates the potential for a gap between true evidence quality and the strength of recommendation.

At a high level, although the technique for ultrasound mapping of the lumbar spine may be similar, the use of ultrasound has been less well studied specifically for LP. When considering $\mathrm{LP}$ alone, the available literature is inadequate to recommend uniform ultrasound guidance. A 2018 meta-analysis by Gottlieb et al. included 12 studies focusing only on LP, totaling $N$ $=957$ patients. ${ }^{.}$This showed some favorability of ultrasound guidance, with a success rate of $90 \%$ using ultrasound, $81.4 \%$ with a landmark-based approach, and an odds ratio of $2.22 \mathrm{fa}$ voring ultrasound guidance ( $95 \% \mathrm{Cl}: 1.03-4.77)$. Unfortunately, when focusing only on adult patients, the advantage of POCUS diminished, with $91.4 \%$ success in the ultrasound group, $87.7 \%$ success in the landmark group, and a nonsignificant odds ratio of 2.10 (95\% Cl: 0.66-7.44).

Unequivocally, POCUS has established itself as a transformative technology for the guidance of invasive bedside procedures, bringing increased procedural success, improved safety, and decreased complication rates. ${ }^{6}$ For some procedures, particularly central venous catheterization, ultrasound guidance is a clear standard of care. ${ }^{7.8}$ For $L P$, the greatest benefit has been observed in patients with anticipated procedural challenges, most commonly obese patients in whom landmarks are not easily palpable. ${ }^{9}$ Moreover, the harms ultrasound seeks to prevent are substantially different. The primary risk of deferring ultrasound guidance for LP is most often a failed procedure, whereas for other common ultrasound-guided procedures, the harms may include significant vascular injury, pneumothorax, or bowel perforation. Differences in the relative harms make risk-benefit assessments harder to quantify and studies harder to carry out.

Sonographic guidance for LP has a role in clinical practice and should always be considered. However, at present, there exist no guidelines in any other specialty regarding the routine use of ultrasound-guided LP, including anesthesia, emergency medicine, neurology, or interventional radiology. ${ }^{10-15}$ As a re- 
sult, a conservative interpretation of the POCUS Task Force's findings would be to consider the use of ultrasound guidance for LP in patients where landmark identification is particularly challenging, but not to consider it a standard requirement for accreditation, training, or practice as of yet. Saying "more studies are required" can be a cop-out in some cases, but in this situation, the old adage does seem to apply.

We have great respect for the work of the SHM POCUS Task Force in advancing the use of POCUS in hospital medicine. Though ultrasound is not currently mandated as a care standard for the performance of LP, we all can agree that POCUS does confer advantages for this procedure, particularly in a well-selected patient population. To continue to provide care of the highest quality, hospitalists must be encouraged to elevate their practice with POCUS and be supported with the equipment, training, credentialing, and quality assurance structures necessary to integrate bedside ultrasound safely and effectively into their diagnostic and procedural practice.

Disclosures: No conflicts of interest to disclose.

Funding: None.

\section{References}

1. Soni NJ, Schnobrich D, Matthews BK, et al. Point-of-care ultrasound for hospitalists: a position statement of the society of hospital medicine. J Hosp Med. 2019;14(10):591-601. https://doi.org/10.12788/jhm.3079.

2. Soni NJ, Franco-Sadud R, Dobaidze K, et al. Recommendations on the use of ultrasound guidance for adult lumbar puncture: a position statement of the society of hospital medicine. J Hosp Med. 2018;13(2):126-135. https://doi. org/10.12788/jhm.2940.

3. Fitch, K, Bernstein SJ, Aguilar MD et al. The RAND/UCLA appropriateness method user's manual. Santa Monica, CA: RAND Corporation, 2001.
4. Guyatt $\mathrm{GH}$, Oxman AD, Vist GE, et al. GRADE: An emerging consensus on rating quality of evidence and strength of recommendations. BMJ. 2008;334(7650):924-926.

5. Gottlieb M, Holladay D, Peksa GD. Ultrasound-assisted lumbar punctures: a systematic review and meta-analysis. Acad Emerg Med. 2019;26(1):85-96. https://doi.org/10.1111/acem.13558.

6. Moore CL, Copel JA. Point of care ultrasonography. $N$ Engl J Med. 2011;364(8):749-757. https://doi.org/10.1056/NEJMra0909487.

7. Shojania K, Duncan B, McDonald K, Wachter RM. Making health care safer: a critical analysis of patient safety practices. Rockville, MD: Agency for Healthcare Research and Quality, 2001. Evidence Report/Technology Assessment No. 43; AHRQ publication 01-E058.

8. Brass P, Hellmich M, Kolodziej L, Schick G, Smith AF. Ultrasound guidance versus anatomical landmarks for internal jugular vein catherization. Cochrane Database Syst Rev. 2015;Art. No.: 1:CD006962. https://doi.org/10.1002/14651858. CD006962.pub2

9. Peterson MA, Pisupati D, Heyming TW, Abele JA, Lewis RJ. Ultrasound for routine lumbar puncture. Acad Emerg Med. 2014;21(2):130-136. https://doi. org/10.1111/acem.12305.

10. American College of Emergency Physicians. Ultrasound guidelines: emergency, point-of-care, and clinical ultrasound guidelines in medicine. Ann Emerg Med. 2017;69(5):e27-e54. https://doi.org/10.1016/j. annemergmed.2016.08.457.

11. Neal JM, Brull R, Horn JL, et al. The Second American Society of Regional Anesthesia and Pain Medicine Evidence-Based Medicine Assessment of UItrasound-Guided Regional Anesthesia: executive summary. Reg Anesth Pain Med. 2016:41(2):181-194. https://doi.org/10.1097/AAP.0000000000000331.

12. Practice guidelines for obstetric anesthesia: an updated report by the American Society of Anesthesiologists Task Force on Obstetric Anesthesia and the Society for Obstetric Anesthesia and Perinatology. Anesthesiology. 2016;124(2):270-300. https://doi.org/10.1097/ALN.0000000000000935.

13. Engelborghs $S$, Sebastiaan E, Struyfs $H$, et al. Consensus guidelines for lumbar puncture in patients with neurological diseases. Alzheimers Dement. 2017;8:111-126. https://doi.org/10.1016/j.dadm.2017.04.007.

14. American College of Radiology. ACR-SPR-SRU Practice Parameter for the Performing and Interpreting Diagnostic Ultrasound Examinations. 2017; Available at https://www.acr.org/-/media/ACR/Files/Practice-Parameters/ us-perf-interpret.pdf. Accessed April 15, 2019.

15. American College of Radiology. ACR-AIUM-SPR-SRU Practice Parameter for the Performance of an Ultrasound Examination of the Neonatal and Infant Spine. 2016/ Available at https://www.acr.org/-/media/ACR/Files/Practice-Parameters/US-NeonatalSpine.pdf. Accessed April 15, 2019 